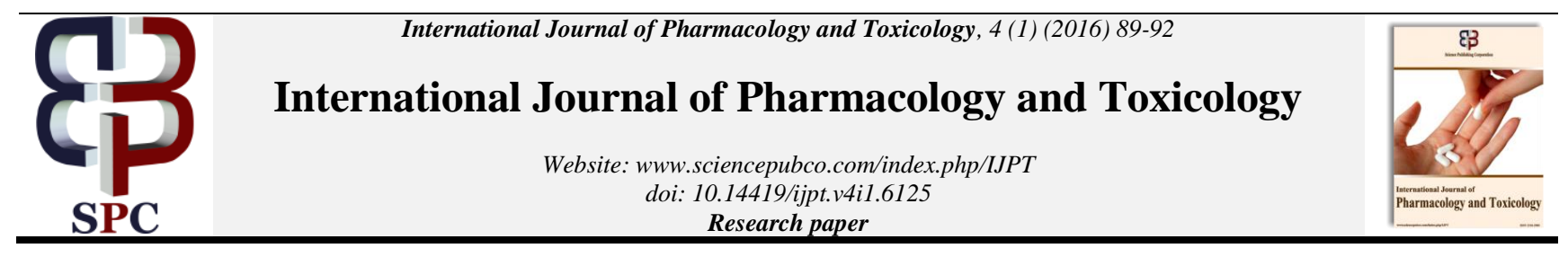

\title{
Comparative endocrine disrupting effects of abamectin and indoxacarb insecticides
}

\author{
Atef Mohamed Khedr NASSAR * \\ Plant Protection Department, Faculty of Agriculture, Damanhour University, Damanhour, Albeheira, 22516, Egypt \\ *Corresponding author E-mail: atef.nassar@dmu.edu.eg
}

\begin{abstract}
Abamectin and indoxacarb are relatively new insecticides with different mode of action and are applied to control a wide range of plant pests. However, their side effects to mammals are not fully studied. Accordingly, current study aimed to compare the adverse effects of both insecticides against the endocrine biomarkers: triiodothyronine (T3), tetraiodothyronine (T4), follicular-stimulating hormone (FSH), progesterone, and testosterone. These parameters were measured after orally-injecting rats with $1 / 20 \mathrm{LD}_{50}$ doses of each of abamectin and indoxacarb for 60 days. Results showed that indoxacarb had pronounced reduction in the contents of T3 and FSH hormones compared to control and abamectin. Also, indoxacarb increased testosterone level compared to abamectin. T4 level was reduced by abamectin treatment compared to indoxacarb. Progesterone content was significantly increased after the abamectin treatment, while it was decreased after the indoxacarb treatment. However, the tested insecticides belong to avermectins and oxadiazine chemical groups that have different mode of action. They showed some similarity in their effect on T3, T4, and FSH, except for the progesterone hormone that showed a contradicting response. These two insecticides were marked as safe but current study highlight the need for caution during their application in the integrated pest management program.
\end{abstract}

Keywords: Insecticides; Avermectins; Oxadiazine; White Albino Rats; Endocrine Biomarkers.

\section{Introduction}

Pesticide development is an ongoing process. Production of new pesticides with different modes of action is a successful strategy to cope with a) the increasing demand for new products for pest management and b) the development of resistance to existing products. Abamectin and indoxacarb are relatively new insecticides with different modes of action and are used extensively to control many pests on different crops. Abamectin is derived from Streptomyces avermitilis, comprises at least $80 \%$ of avermectin $\mathrm{B}_{1 \mathrm{a}}$ and $20 \%$ of avermectin $\mathrm{B}_{1 \mathrm{~b}}$ and is currently used as an insecticide, acaricide, and anthelmintic (Tomlin, 2004; Kolar et al., 2008).

Abamectin was introduced in 1985 as the lead member of the avermectins. It kills pests by interfering with the function of $\gamma$ aminobutyric acid (GABA) receptor in the peripheral nervous system and blocking the electrical activity in nerves and muscles (Clark et al., 1995). Specifically, it was reported that the target site for avermectins in insects and nematodes were glutamate-gated chloride channel, $\gamma$-aminobutyric acid (GABA)-gated chloride channel, and histamine-gated chloride channel (Turner and Schaeffer, 1989; Korystov et al., 1999; McCavera et al., 2007; Abd-Elhady and Abou-Elghar, 2013).

Abamectin is being used to controls leaf miners and mites on vegetable and fruit crops in the US, Brazil, Mexico, Italy, Egypt, France, Spain, Indonesia and Argentina (BASF, 2013). Although it was reported as toxic pesticide to fish, mammals and aquatic organisms (Lankas and Gordon, 1989; Abd-Elhady, 2012; BASF, 2013; IRAC, 2016). Moreover, abamectin showed maternal toxicity after a two-generation reproductive toxicity study on mice and rats (Lankas and Gordon, 1989; Pacqué et al., 1990; Abd-Elhady,
2012). Reproductive toxicity was reported for abamectin but no side effect was noticed on the testosterone hormone content after orally-injecting rats with doses of 1 and $4 \mathrm{mg} \mathrm{kg}^{-1}$ daily in subacute and sub-chronic studies (Celik-Ozenci et al., 2011). Also, the fertility was significantly reduced in male rats ingested abamectin at $10 \mathrm{mg} \mathrm{kg}^{-1}$ bw $\left(1 / 30 \mathrm{LD}_{50}\right)$ for 210 days once a week (Abd-Elhady and Abou-Elghar, 2013).

In parallel to abamectin, indoxacarb (methyl (S)-N-[7-chloro-2, 3, 4a, 5-tetrahydro-4a-(methoxycarbonyl)indeno[1, 2-e] [1], [3], [4]oxadiazin-2-ylcarbonyl]-4'-(trifluoro methoxy) carbanilate) was the first commercial broad-spectrum insecticide from the oxadiazine group (Tomlin, 2004). It belongs to the IRAC toxicity group number 22A, where it exerts its mode of action (insecticidal activity) through blocking of the voltage-dependent sodium channel (IRAC, 2016). It's been used on vegetables mainly against the insects of the Lepidoptera, Coleoptera, Hemiptera, Diptera, Orthoptera, and Hymenoptera (Wing et al., 1998; Liu et al., 2002; BASF, 2013). It has a selective action with no effects on nontarget insects and it blocks the movement of sodium ion and stops insects feeding and paralysis (Dinter and Wiles, 2000).

However, indoxacarb was reported to be bioactivated inside the insects by amidases and esterases but catabolized in mammals (BASF, 2013; IRAC, 2016). Studies showed delayed toxicity on mice and rats after 14 days of administration of a single dose equal to the maximum tolerated oral dose (MTD $=500 \mathrm{mg} \mathrm{kg}^{-1}$ ) (Shit et al., 2008). Also, chronic exposure (30 day) to indoxacarb caused deleterious oxidative stress effects as appeared on the lipid, protein, and glutathione content and glutathione-S-transferase, superoxide dismutase, and catalase enzyme activities of mice administered-orally with 6,812 and $24 \mathrm{mg} \mathrm{kg}^{-1} \mathrm{~d}^{-1}$ (Mudaraddi et al., 2012). Studies on the adverse effects of these two insecticides on the endocrine system of mammals are limited. Therefore, current 
study was designed to compare the sub-chronic side effects of abamectin and indoxacarb on steroid and reproductive hormones of male rats.

\section{Materials and methods}

\subsection{Chemicals and pesticides}

Commercial kits of follicle stimulating hormone (FSH), progesterone, testosterone, triiodothyronine (T3), and thyroxine (T4) hormones were provided from reputed local chemical company. The commercial formulation of abamectin (Vertemic ${ }^{\circledR}, 1.8 \% \mathrm{EC}$ ) and indoxacarb (Avaunt ${ }^{\circledR}, 15 \%$ SC) were supplied by Syngenta Agro Services AG, Egypt.

\subsection{Animals and treatments}

Male albino rats (Rattus norvegicus) $(110 \pm 10 \mathrm{~g})$ were obtained from the Research Institute of Ophthalmology, Giza, Egypt. Animals were housed in small groups (5 each) inside propylene cages $(25 \times 50 \mathrm{~cm})$ at $25 \pm 2{ }^{\circ} \mathrm{C}, 12 \mathrm{~h}$ dark/light photoperiod, and $70 \pm 10$ $\%$ RH. Rats were fed with commercial pelleted rodent feed and water ad libitum. The animals were acclimatized to laboratory conditions for two weeks, and then divided into three groups of five adult males each. Rats in group-1 were administered $15 \mathrm{mg}$ $\mathrm{kg}^{-1}$ b.w. $\left(1 / 20 \mathrm{LD}_{50}\right)$ of abamectin, group-2 rats were orallyinjected with $86.6 \mathrm{mg} \mathrm{kg}^{-1}$ b.w. $\left(1 / 20 \mathrm{LD}_{50}\right)$ of indoxacarb. The third group of rats were orally-given equal volume of the solvent (distilled water) that was used to prepare the insecticide doses. Rats were given oral doses for 60 days. Handling of the experimental animals was consistent with the international principles on the care and use of experimental animals (National Research Council, 2011).

\subsection{Blood collection}

The animals from the three groups were sacrificed 24 hours after the last treatment. Rats were anesthetized using diethyl ether for $10 \mathrm{~s}$ before the neck vessels were aseptically severed. Blood was collected in $15 \mathrm{~mL}$ screw cap test tubes. Serum was separated by centrifugation of blood samples at 4,000 rpm for $10 \mathrm{~min}$ (Universal 32R, Hettich Zentrifugen model D-78532, Germany). Serum was stored in $200 \mu \mathrm{L}$ portions in Eppendorf tubes at $-20^{\circ} \mathrm{C}$ until analysis.

\subsection{Estimation of hormones content}

Serum samples were used to estimate their contents of FSH, T3, $\mathrm{T} 4$, testosterone, and progesterone hormones. Follicle-stimulation hormone (FSH). Determination was carried out according to the method reported by Marshall (1975) and Rebar et al. (1982) using International Immuno Diagnostics kits. Concentrations of FSH in mlU $\mathrm{mL}^{-1}$ was estimated from a standard curve. Testosterone hormone determination was carried out according to the method reported by Granoff and Abraham (1979) and Tietz (1995) using the International Immuno Diagnostics kits and was expressed as ng $\mathrm{mL}^{-1}$. Triiodothyronine (T3) hormone determination was carried out according to the method reported by Burke and Eastman (1974) using the International Immuno Diagnostics kits and expressed as $\mathrm{ng} \mathrm{mL}^{-1}$. Determination of the $\mathrm{T} 4$ hormone was carried out according to the method reported by Skelley et al. (1973) using the International Immuno Diagnostics kits and expressed as ng $\mathrm{mL}^{-1}$ from a standard curve. Progesterone content was determined according to the method reported by Cameron and Scarisbrik (1973) and Kakabakos and Khosravi (1992) and expressed in ng $\mathrm{mL}^{-1}$.

\section{Method validation}

\subsection{Accuracy and precision}

Accuracy and precision were evaluated using five concentrations $\left(0.5,1,2.5,5\right.$, and $7.5 \mathrm{ng} \mathrm{mL}^{-1}$ of $\mathrm{T} 3,2,5,10,15$, and $25 \mu \mathrm{g} \mathrm{dL}^{-1}$ of T4, 5, 15, 50, 100, and $200 \mathrm{mlU} \mathrm{mL}^{-1}$ of FSH, 0.5, 3, 10, 25, and $50 \mathrm{ng} \mathrm{mL}^{-1}$ of progesterone, and $0.1,0.5,2,6$, and $18 \mathrm{ng} \mathrm{mL}^{-1}$ of testosterone) within the same day to obtain repeatability (intraassay precision) and over 5 consecutive days to obtain intermediate precision (inter-assay precision). The accuracy and precision were calculated and expressed in terms of percent recovery and coefficient of variation (CV \%), respectively (Ermer, 2005).

\subsection{Statistical analysis}

The present study was designed as an oral sub-chronic toxicity study. Results were analyzed using the General Linear Model (GLM) procedure of statistical analysis system as one way analysis of variance (one-way-ANOVA) (SAS version 9.3). Significant means were compared using Tukey-Kramer Honestly Significant Difference (HSD) post-hoc multiple comparison test $(\mathrm{P}<0.05)$ (SAS, 2013).

\section{Results and discussions}

The reproducibility of the analysis methods of T3, T4, FSH, testosterone, and progesterone were presented in Table 1 . The interassay values $(\mathrm{n}=25)$ ranged from $6.58-8.64 \%$ and intra-assay $(\mathrm{n}$ $=5$ ) values were between 7.04 and $10.54 \%$. These results were within the acceptable range and confirm that the analytical techniques were reliable.

Table 1: Summary of statistical analysis and percentages of the inter- and intra-assay values of tested hormones.

\begin{tabular}{lcccccc}
\hline Variable & Mean & $\mathbf{R}^{2}$ & $\begin{array}{c}\mathbf{F} \\
\text { value }\end{array}$ & $\operatorname{Pr}>\mathbf{F}$ & $\begin{array}{r}\text { Inter- } \\
\text { Assay }\end{array}$ & $\begin{array}{c}\text { Intra- } \\
\text { Assay }\end{array}$ \\
\hline $\begin{array}{l}\text { Triiodothyronine } \\
\text { (T3) }\end{array}$ & 0.60 & 0.94 & 75.70 & $<0.0001$ & 7.15 & 10.05 \\
$\begin{array}{l}\text { Tetraiodothyronine } \\
\text { (T4) }\end{array}$ & 6.83 & 0.94 & 62.21 & $<0.0001$ & 6.97 & 9.24 \\
$\begin{array}{l}\text { Follicle-Stimulating } \\
\text { Hormone (FSH) }\end{array}$ & 10.16 & 0.93 & 60.15 & $<0.0001$ & 8.64 & 10.54 \\
$\begin{array}{l}\text { Progesterone } \\
\text { Testosterone }\end{array}$ & 0.41 & 0.88 & 31.77 & $<0.0001$ & 7.83 & 8.71 \\
& 3.52 & 0.67 & 9.09 & 0.0069 & 8.06 & 9.16 \\
\hline
\end{tabular}

\subsection{Effects of abamectin and indoxacarb on hormones adverse effects on thyroid hormones}

Hormones are required for normal growth, development and metabolism of cells (Yen, 2001; Puri, 2011). Hormones are produced in the blood via several glands for example the thyroid gland, is the largest gland in humans, produces two principal hormones: thyroxine (tetra-iodothyronine; T4) and tri-iodothyronine (T3) (Puri, 2011). Both T3 and T4 are bio-indicators of the hypothalamus and pituitary glands activities (Kirsten, 2000; Mebis et al., 2008). These hormones have important function in the body, specifically the stimulation of metabolism (Puri, 2011; Quraishi et al., 2015). T3 and T4 help acquiring the element iodine and convert it into the form that is biologically available (Granner, 2003). Abamectin significantly decrease the content of both T4 and T3 hormones compared to control (Figure 1). Percentages of reduction of T4 and T3 compared to control were -50 and $-45 \%$, respectively. Also, indoxacarb reduced the concentration of both $\mathrm{T} 4$ and $\mathrm{T} 3$ hormones by -39 and $-60 \%$, respectively compared to the control group (Figure 2). 


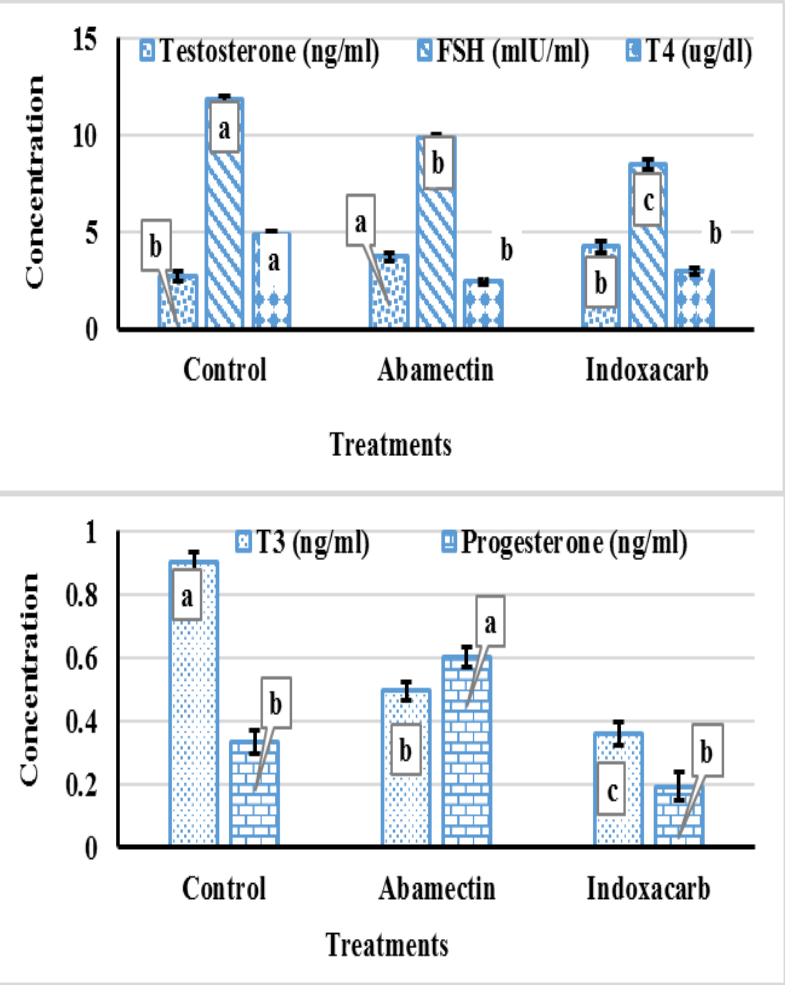

Figure 1. LS Mean values of content of (A) testosterone (ng mL $\left.{ }^{-1}\right)$, follicle-stimulating hormone (FSH) $\left(\mathrm{mIU} \mathrm{mL}^{-1}\right)$, and tetraiodothyronine (T4) ( $\mu \mathrm{g} \mathrm{dL}^{-1}$ ) and (B) contents of triiodothyronine (T3)

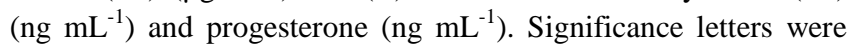
based on Tukey-Kramer Honestly Significant Difference (HSD) post-hoc multiple comparison test $(P<0.05)$. Charts were plotted in single graph based on similarity of the vertical scale value.

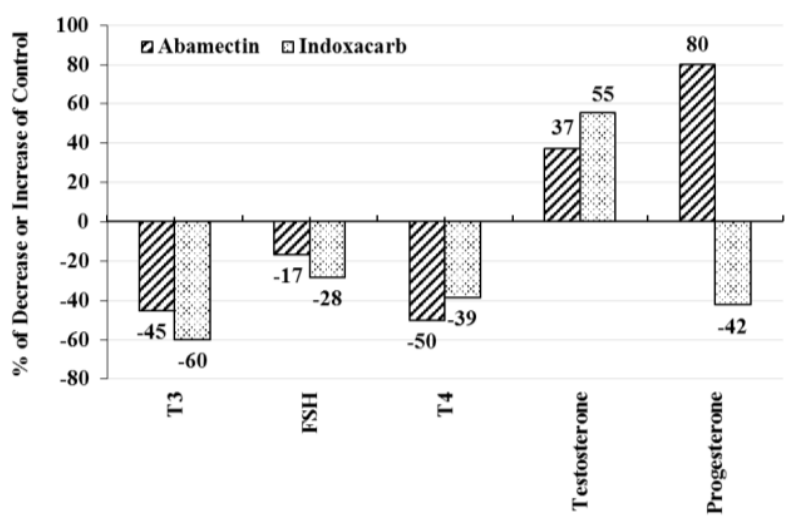

Figure 2. Percentages of decrease or increase of the contents of triiodothyronine (T3) (ng $\left.\mathrm{mL}^{-1}\right)$, follicle-stimulating hormone (FSH) $\left(\mathrm{mIUml}^{-1}\right)$, tetraiodothyronine $(\mathrm{T} 4)\left(\mu \mathrm{g} \mathrm{dL}^{-1}\right)$, testosterone $\left(\mathrm{ng} \mathrm{mL} \mathrm{L}^{-1}\right)$, and progesterone $\left(\mathrm{ng} \mathrm{mL}^{-1}\right)$.

\subsection{Adverse effects on pituitary gland hormones}

Follicular-stimulating hormone (FSH) is released from the gonadotropes in the pituitary gland (Puri, 2011). In women, FSH stimulates the aromatization of androgens to estrogens in the ovary, while in men, it works with testosterone in Sertoli cells in the testes to support spermatogenesis (Langouche and Berghe, 2008; Puri, 2011). Pesticides interfere with the normal function of FSH, where abamectin and indoxacarb significantly reduced the content of FSH hormone (Figure 1). Reduction were of -17 and $-28 \%$ for abamectin and indoxacarb, respectively compared to control (Figure 2). So, these two insecticides would change FSH function in testes, which might affect the sperm formation and/or viability.

\subsection{Adverse effects on steroid hormones}

Testosterone works in association with FSH for normal spermatogenesis (Puri, 2011). FSH promotes the secretion of androgen binding protein, which permits high concentration of testosterone. It is necessary for spermatogenesis in seminiferous tubules (Puri, 2011). Both abamectin and indoxacarb increased the levels of testosterone (Figure 1) by 37 and 55\%, respectively compared to control (Figure 2).

Progesterone is produced and secreted by the corpus luteum (Granner, 2003; Puri, 2011). Difference effects were found for abamectin and indoxacarb on progesterone. Abamectin significantly increased, while indoxacarb decreased the content on progesterone (Figure 1). Percentages of increase and decrease compared to control were 80 and $-42 \%$ for abamectin and indoxacarb, respectively (Figure 2). These results were not in line with that of Celik-Ozenci et al. (2011). They reported that abamectin pose no adverse effects on testosterone hormone after orally injecting rats daily with doses of 1 and $4 \mathrm{mg} \mathrm{kg}^{-1}$ in subacute and sub-chronic studies. On the other hand, fertility of rats was significantly reduced after ingesting abamectin at $10 \mathrm{mg} \mathrm{kg}^{-1}$ b.w. $\left(1 / 30 \mathrm{LD}_{50}\right)$ for 210 days, once a week (Abd-Elhady and Abou-Elghar, 2013).

\section{Conclusions}

Indoxacarb showed pronounced reduction effect in T3 and FSH and an increase in the testosterone content compared to abamectin. Only T4, which was affected (reduced) after the abamectin treatment. Almost all of the tested biochemical parameters were affected similarly after both treatments of abamectin and indoxacarb except for the progesterone hormone, which showed different response to both insecticides. Progesterone was significantly increased after the abamectin treatment, while it was decreased after the indoxacarb treatment. The tested insecticides belong to avermectins and oxadiazine and exert their insecticidal effect with different mode of action blockers of GABA and sodium channel, respectively. They showed similarity in affecting T3, T4, and FSH except for progesterone hormone that showed contradicting response.

\section{Acknowledgements}

The author would like to thank Prof. Dr. Moustafa A. Abbassy (Professor of Pesticide Chemistry and Toxicology, Plant Protection Department, Faculty of Agriculture, Damanhour University) for the revision of the manuscript. Also, I would like to thank Dr. Yehia M. Salim (Assistant Professor of Pesticide Chemistry and Toxicology, Plant Protection Department, Faculty of Agriculture, Damanhour University) for his help with the laboratory assays.

\section{References}

[1] Abd-Elhady, H.K. (2012). Insecticidal activity and chemical composition of essential oil from Artemisia judaica L. against Callosobruchus maculates (F.) (Coleoptera: Bruchidae). J Plant Prot Res 52: 347-352. http://dx.doi.org/10.2478/v10045-012-0057-9.

[2] Abd-Elhady, H.K. and G.E. Abou-Elghar (2013) Abamectin induced biochemical and histopathological changes in the albino rat, Rattus norvegicus. Journal of Plant Protection Research 53: 263270. http://dx.doi.org/10.2478/jppr-2013-0039.

[3] Abd-Elhady, H.K. and H.M. Heikal (2011) Selective toxicity of three acaricides to the two-spotted spider mite Tetranychus urticae and predatory mite Phytoseuilus persimilis in apple orchards. J Entomol 8: 574-580. http://dx.doi.org/10.3923/je.2011.574.580.

[4] BASF (2013). Insecticide Mode of Action. Technical Training Manual. Crop Protection Division. Global Strategic Marketing, Insecticides. BASF Corporation. GL-8006A December 2013. www.agro.basf.com

[5] Burke, C.W. and C.J. Eastman (1974) Thyroid hormones. Brit Med Bull 30: 93-99. 
[6] Cameron, E.D.H. and J.J. Scarisbrik (1973) Radioimmuno assay of plasma progesterone. Clin Chem 19: 1403-1408.

[7] Celik-Ozenci, C., A. Tasatargil, M. Tekcan, L. Sati, E. Gungor, M. Isbir, and R. Demir (2011) Effects of abamectin exposure on male fertility in rats: Potential role of oxidative stress-mediated poly (ADP-ribose) polymerase (PARP) activation. Regulatory Toxicology and Pharmacology 61: 310-317. http://dx.doi.org/10.1016/j.yrtph.2011.09.001.

[8] Clark, J.M., J.G. Scott, F. Campos, and J.R. Bloomquist (1995) Resistance to avermectins: extent, mechanisms, and management implications. Annu Rev Entomol 40: 1-30. http://dx.doi.org/10.1146/annurev.en.40.010195.000245.

[9] Dinter, A. and A.J. Wiles (2000) Safety of the new Dupont insecticide indoxacarb to beneficial arthropoda an overview. IOBC/Wp RS Bulletin 23: 149-156.

[10] Ermer, J. (2005) Performance parameters, calculations and tests. In: Method Validation in Pharmaceutical Analysis. A Guide to Best Practice, ed. J. Ermer and J.H. McB Miller. Weinheim: WilleyVCH Verlag $\mathrm{GmbH} \quad \& \quad$ Co. KGaA. Ch 2 http://dx.doi.org/10.1002/3527604685.ch2.

[11] Granner, D.K. (2003) the Diversity of the Endocrine System. In Harper's Illustrated Biochemistry. Twenty-sixth edition. R.K. Murray, D.K. Granner, P.A. Mayes, and V.W. Rodwell. Lange Medical Books/McGraw-Hill. Medical Publishing Division. Ch 42.

[12] Granoff, A.B. and G.E. Abraham (1979) Peripheral and adrenal venouse levels of steroids in a patient with virilizing adenoma. Obstet Gynecol 53: 111

[13] IRAC (Insecticide Resistance Action Committee) (2016) IRAC Mode of Action Classification Scheme. Version 8.1. www.iraconline.org (April 2016).

[14] Kakabakos, S.E. and M.J. Khosravi (1992) direct time resolved florescence immunoassay of progesterone in serum involving the biotin streptavidin system and the immobilized antibody approach. Clin Chem 38: 725-730.

[15] Kirsten, D. (2000) the thyroid gland: physiology and pathophysiology. Neonatal network: J Neonat Nurs 19: 11 http://dx.doi.org/10.1891/0730-0832.19.8.11.

[16] Kolar, L., N.K. Erzen, L. Hogerwerf, and C.A.M. Van Gestel (2008) Toxicity of abamectin and doramectin to soil invertebrates. Environ Pollut 151: 182-189. http://dx.doi.org/10.1016/j.envpol.2007.02.011.

[17] Korystov, Y.N., V.A. Mosin, V.V. Shaposhnikova, M.K. Levitman, A.A. Kudryavtsev, E.B. Kruglyak, T.S. Sterlina, A.V. Viktorov, and V.A. Drinyaev (1999) A comparative study of effects of aversectin $\mathrm{C}$, abamectin and ivermectin on apoptosis of rat thymocytes induced by radiation and dexamethasone. Acta Vet BRNO 68: 2329. http://dx.doi.org/10.2754/avb199968010023.

[18] Langouche, L. and G. Van den Berghe (2008) The Dynamic Neuroendocrine Response to Critical Illness. In: Van den Berghe, G (Ed.). Contemporary Endocrinology: Acute Cause to Consequence. Humana Press, New York, http://dx.doi.org/10.1007/978-1-60327177-6.

[19] Lankas, G.R. and L.R. Gordon (1989) Toxicology. In: Campbell, WC (Ed.), Ivermectin and Abamectin. Springer-Verlag, New York, pp. 10-142 http://dx.doi.org/10.1007/978-1-4612-3626-9_6.

[20] Liu, T.X., Jr. A.N. Sparks, W. Chen, G.M. Liang, and C. Brister (2002) Toxicity, persistence and efficacy of indoxacarb on cabbage looper (Lepidoptera: Noctuidae) on cabbage. Economic Entomol 92: 360-367. http://dx.doi.org/10.1603/0022-0493-95.2.360.

[21] Marshall, J.C. (1975) Clinic in Endocrinol Metab 4: 545 http://dx.doi.org/10.1016/S0300-595X(75)80047-8.

[22] McCavera, S., T.K. Walsh, and A.J. Wolstenholme (2007) Nematode ligand-gated chloride channels: an appraisal of their involvement in macrocyclic lactone resistance and prospects for developing molecular markers. Parasitology 134: 1111-1121. http://dx.doi.org/10.1017/S0031182007000042.

[23] Mebis, L., L. Langouche, and G. Van den Berghe (2008) Changes within the thyroid axis during the course of critical illness. In: Van den Berghe, G (Ed.). Contemporary Endocrinology: Acute Cause to Consequence. Humana Press, NY. http://dx.doi.org/10.1007/978-1 60327-177-6.

[24] Mudaraddi, T.Y., R.R. Potadar, and B.B. Kaliwal (2012) Indoxacarb induces liver oxidative stress in Swiss Albino Mice. European Journal of Experimental Biology 2: 180-186.

[25] National Research Council (2011) Guide for the Care and Use of Laboratory Animals, $8^{\text {th }}$ ed.; the National Academies Press: Washington, DC, USA.

[26] Pacqué, M., B. Muñoz, G. Poetschke, J. Foose, B.M. Greene, and H.R. Taylor (1990) Pregnancy outcome after inadvertent ivermectin treatment during community-based distribution. Lancet 336: 14861489. http://dx.doi.org/10.1016/0140-6736(90)93187-T.

[27] Puri, D. (2011) Textbook of Medical Biochemistry, $3^{\text {rd }}$ Edition. Elsevier, A division of Reed Elsevier India Private Limited. ISBN 978-81-312-2312-3.

[28] Quraishi, R., F. Akbar, S. Karim, S. Ahmad, W. Rashid, and S. U1lah (2015) Effects of pesticides on haematology, Thyroid stimulating hormone (TSH) and tri-iodothyronine (T3) hormones of agricultural workers in Swat, Pakistan. J Biol Life Sci 6: 96-107.

[29] Rebar, R.W., G.F. Erickson, and S.S.C. Yen (1982) Fertil Steril 37: 35. http://dx.doi.org/10.1016/S0015-0282(16)45973-X.

[30] SAS (Statistical Analysis System) (Version 9.2) (2013) SAS Institute Inc., Cary, NC 27513-2414 USA.

[31] Seixas, J.N., P.V. Peixoto, A.G. Armién, F.F. Jabour, and M.F. Brito (2006) Clinical and pathogenetic aspects of abamectin poisoning in calves. Pesq Vet Bras 26: 161-166. http://dx.doi.org/10.1590/S0100-736X2006000300006.

[32] Shit, S.P., R.S Panghal, V. Kumar, and R.D. Rana (2008) Acute toxicity and gross behavioural effects of indoxacarb in laboratory animals. Haryana Vet 47: 49-51.

[33] Skelley, D., L. Brown, and P. Besch (1973) Radioimmunoassay. Clin Chem 19: 146

[34] Tomlin, C.D.S. (Ed.) (2004) A world compendium. The e-Pesticide Manual. Thirteen's Edition. Version 3.0 2003-04. British Crop Protection Council (BCPC).

[35] Turner, M.J. and J.M. Schaeffer (1989) Mode of action of ivermectin. In: Campbell, WC (Ed.), Ivermectin and Abamectin. SpringerVerlag, New York, pp. 73-78. http://dx.doi.org/10.1007/978-14612-3626-9 5.

[36] Wing, K.D., M.E. Schnee, M. Sacher, and M. Connair (1998) A novel oxadiazine insecticide is bioactivated in lepidopteran larvae. Archive Insect Biochem Physiol 37: 91-103. http://dx.doi.org/10.1002/(SICI)1520-6327(1998)37:1<91::AIDARCH11>3.0.CO;2-5.

[37] Yen, P.M. (2001) Physiological and molecular basis of thyroid hormone action. Physiol Rev 81: 1097-1142. 